\title{
Raman spectroscopic study of cervical precancerous lesions and cervical cancer
}

\author{
Jing Wang ${ }^{1} \cdot$ Cheng-Xia Zheng ${ }^{2}$ - Cai-Ling Ma ${ }^{1} \cdot$ Xiang-Xiang Zheng ${ }^{3} \cdot$ Xiao-Yi Lv ${ }^{2} \cdot$ Guo-Dong Lv ${ }^{1}$ - Jun Tang ${ }^{4}$. \\ Guo-Hua $\mathrm{Wu}^{3}$
}

Received: 2 May 2019 / Accepted: 7 December 2020 / Published online: 6 January 2021

(C) The Author(s) 2021

\begin{abstract}
Early detection of cervical lesions, accurate diagnosis of cervical lesions, and timely and effective therapy can effectively avoid the occurrence of cervical cancer or improve the survival rate of patients. In this paper, the spectra of tissue sections of cervical inflammation ( $n=60)$, CIN (cervical intraepithelial neoplasia) I ( $n=30)$, CIN II $(n=30)$, CIN III $(n=30)$, cervical squamous cell carcinoma $(n=30)$, and cervical adenocarcinoma $(n=30)$ were collected by a confocal Raman micro-spectrometer (LabRAM HR Evolution, Horiba France SAS, Villeneuve d'Ascq, France). The Raman spectra of six kinds of cervical tissues were analyzed, the dominant Raman peaks of different kinds of tissues were summarized, and the differences in chemical composition between the six tissue samples were compared. An independent sample $t$ test $(p \leq 0.05)$ was used to analyze the difference of average relative intensity of Raman spectra of six types of cervical tissues. The difference of relative intensity of Raman spectra of six kinds of tissues can reflect the difference of biochemical components in six kinds of tissues and the characteristic of biochemical components in different kinds of tissues. The classification models of cervical inflammation, CIN I, CIN II, CIN III, cervical squamous cell carcinoma, and cervical adenocarcinoma were established by using a support vector machine (SVM) algorithm. Six types of cervical tissues were classified and identified with an overall diagnostic accuracy of $85.7 \%$. This study laid a foundation for the application of Raman spectroscopy in the clinical diagnosis of cervical precancerous lesions and cervical cancer.
\end{abstract}

Keywords Cervical cancer $\cdot$ Cervical intraepithelial neoplasia $\cdot$ Cervix tissues $\cdot$ Raman spectroscopy $\cdot$ Support vector machine (SVM)

Cai-Ling Ma

hymc113009661999@126.com

Xiao-Yi Lv

xiaoz813@163.com

1 State Key Laboratory of PPTHIDCA/Department of Gynecology, The First Affiliated Hospital of Xinjiang Medical University, Urumqi 830054, China

2 College of Information Science and Engineering, Xinjiang University, Urumqi 830046, China

3 School of Electronic Engineering, Beijing University of Posts and Telecommunications, Beijing 100876, China

4 Physics and Chemistry Detecting Centre, Xinjiang University, Urumqi 830046, China

\section{Introduction}

Cervical cancer is the fourth most common cancer in the world in both morbidity and mortality, and the second most common cancer among women [1]. In some countries where screening systems for cervical cancer have been established, the incidence of cervical cancer has dropped by $65 \%$ in the past 40 years $[2,3]$. However, in recent years, the incidence and mortality of cervical cancer in China have shown a significant upward trend, and the age of onset is trending younger $[2,3]$. Cervical inflammation is common in women, and while chronic cervicitis is curable, long-term inflammatory cervical infections carry a $25 \%$ chance of inducing cervical cancer [4]. The occurrence of cervical cancer is a relatively slow process. Before developing into invasive cervical cancer, lesions must progress through the precancerous stage (CIN I, CIN II, CIN III). The precancerous stage may last for several years. Precancerous lesions of cervical cancer have a high potential 
to be cured. However, there are differences in treatment between cervical squamous cell carcinoma and cervical adenocarcinoma [2]. Therefore, early detection of cervical lesions, correct diagnosis of cervical lesions, and timely and correct treatment measures can effectively avoid the occurrence of cervical cancer or improve the survival rate of patients.

At present, the main screening methods for cervical precancerous lesions and cervical cancer are Thinprep cytologic test (TCT), human papillomavirus (HPV) screening, and combined TCT and HPV screening [1]. Colposcopy and biopsy are recommended for screening abnormal patients. In the past 30 years, the incidence of cervical squamous cell carcinoma has declined significantly in developed countries due to the cervical cancer screening project, but the incidence of cervical adenocarcinoma has increased. This may be due to the poor screening efficacy of cervical cytology screening methods for cervical adenocarcinoma [4]. In addition, these screening methods are time-consuming, costly, and invasive, so it is very important to find a rapid, economical, non-invasive, and objective diagnostic method for cervical lesions (including cervical adenocarcinoma).

Raman spectroscopy is a kind of inelastic scattering spectroscopy, which can quickly, objectively, and accurately detect slight differences between biochemical components of tissues. When used in combination with powerful multivariate algorithms, Raman spectroscopy can potentially provide automated, objective, and reproducible classification of pathology in clinically relevant time frames [5-7].

For example, Jess et al. used Raman spectroscopy to identify between primary human keratinocytes (PHK), PHK cells expressing the E7 gene of HPV-16 (PHK E7), and cervical cancer cells expressing HPV-16 (CaSki). This study was able to distinguish between normal keratinocytes and keratinocytes expressing HPV-16 E7, with a sensitivity and specificity of 93\% and 93\%, respectively [8]. Kim et al. used Raman spectroscopy to detect early HPV infection and cervical dysplasia without labels and achieved a better effect [9]. Duraipandian et al. explored the clinical application value of near-infrared Raman spectroscopy and genetic algorithms-partial least squares-discriminative analysis in colposcopy examination to identify the biomolecular changes in cervical tissues associated with malformation transformation. The established model in this study has a correct rate of $83 \%$ [10].

In this study, six types of cervical tissues were classified and identified by Raman spectroscopy combined with support vector machine (SVM) algorithm. Satisfactory diagnostic results were obtained. At present, an endoscopic Raman spectroscopy nasopharyngeal cancer detector has been developed to clinical application $[11,12]$. It is believed that through further research, there is potential to develop a rapid, objective, economic, and non-invasive endoscopic Raman spectroscopy instrument for cervical lesion detection, which can be used clinically.

\section{Materials and methods}

\section{Patients and ethics statement}

The subjects of this study included cervical fluid-based cytology and/or high-risk HPV-positive patients who underwent cervical biopsy under colposcopy. A total of 210 patient samples were collected, including 60 cases of cervicitis, 30 cases of CIN I, 30 cases of CIN II, 30 cases of CIN III, 30 cases of cervical squamous cell carcinoma, and 30 cases of cervical adenocarcinoma. This study was approved by the ethics committee of Xinjiang Medical University, and the approval number is 20171123-12.

\section{Preparation of cervical tissue}

Two hundred ten tissue sections from 210 patients (Among them, 60 were diagnosed as cervicitis, 30 were diagnosed as CIN I, 30 were diagnosed as CIN II, 30 were diagnosed as CIN III, 30 were diagnosed as cervical squamous cell carcinoma, and 30 were diagnosed as cervical adenocarcinoma by pathological diagnosis of the First Affiliated Hospital of Xinjiang Medical University.) were dewaxed and used in this study. The cervical tissue slices used in this study were prepared by professional doctors. The prepared tissue slices were stored in a dry and ventilated environment before dewaxing, and the preservation temperature was $25 \pm 1{ }^{\circ} \mathrm{C}$. The tissue slices after dewaxing were also stored in a dry and ventilated environment at a temperature of $25 \pm 1{ }^{\circ} \mathrm{C}$.

\section{Histopathological features}

Figure 1 shows the representative micrographs of 6 types of tissues (cervicitis tissue, CIN I, CIN II, CIN III, cervical squamous cell carcinoma, and cervical adenocarcinoma). As can be seen from Fig. 1, the morphological differences of the six kinds of tissues are obvious and easy to distinguish. Specifically, Fig. 1a shows the cervicitis tissue, from which it can be seen that there were a large number of lymphocytes, plasma cells, and other chronic inflammatory cells in the cervical interstitium, which could be accompanied by hyperplasia of the cervical gland epithelium and interstitium and squamous metaplasia. Figure $1 \mathrm{~b}$ shows the CIN I tissue, from which it can be seen that squamous basal and subbasal cell hyperplasia, mild dysplasia of nuclear polarity, mild atypia, few mitotic images, these cells confined to subepithelial 1/3 layer, P16 staining negative or spot-positive scattered in the epithelium. Figure 1c shows the CIN II tissue, from which it can be seen that the nuclear polarity was moderately disordered, with moderate atypia and increased mitotic images, and the heterotypic cells expand to the subepithelial $2 / 3$ layer. Figure $1 \mathrm{~d}$ shows the CIN III tissue, from which it can be 
Fig. 1 Representative

micrographs of 6 types of tissues. a Photomicrograph of cervicitis tissue. b Photomicrograph of CIN I tissue. $\mathbf{c}$ Photomicrograph of CIN II tissue. d Photomicrograph of CIN III tissue. e

Photomicrograph of cervical squamous cell carcinoma. $\mathbf{f}$ Photomicrograph of cervical adenocarcinoma

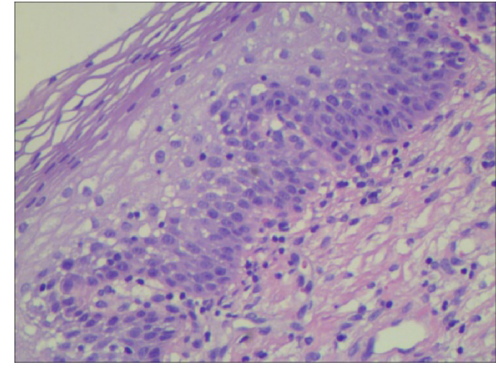

(a)

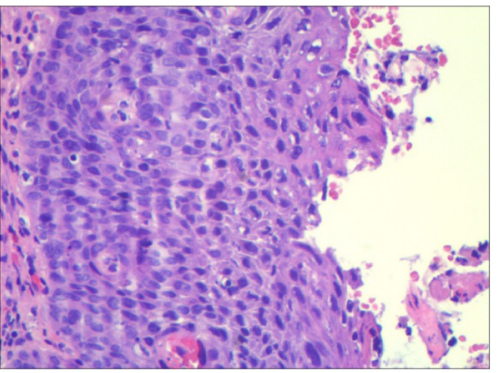

(c)

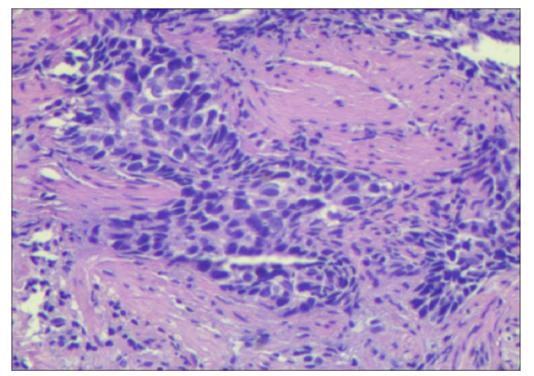

(e)

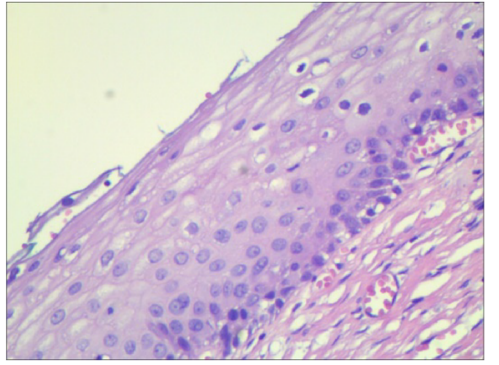

(b)

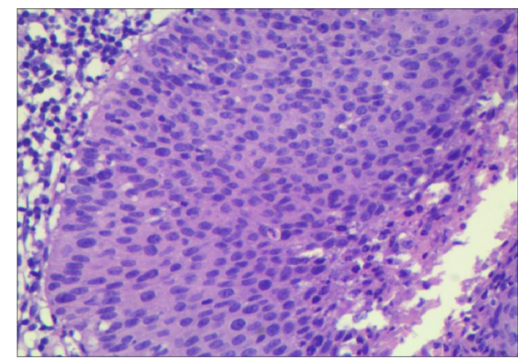

(d)

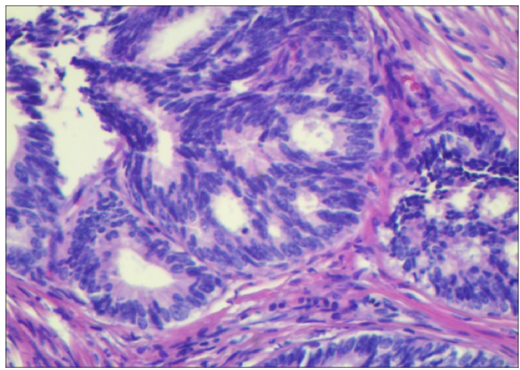

(f) seen that the nuclear polarity was completely disordered, the proportion of nuclear cytoplasm increased significantly, the mitotic images increased, and the heterotypic cells expanded to the whole subepithelial layer. P16 showed diffuse and continuous positive in more than two-thirds of the epithelial layer. Figure 1e shows the cervical squamous cell carcinoma tissue, from which it can be seen that infiltrating squamous cell carcinoma referred to the degree of cervical interstitial invasion beyond the microinvasive carcinoma, which mainly presented as a network or mass infiltration. There were three levels of differentiation: high (grade I), middle (grade II), and low (grade III) differentiation. Figure $1 \mathrm{f}$ shows the cervical adenocarcinoma tissue, from which it can be seen that there were three types, mucinous adenocarcinoma was the most common type, the tumor originated from the cervical mucous membrane columnar mucous cells, the gland structure could be seen under the microscope, and there were papillary processes in the gland cavity, glandular epithelial hyperplasia for multiple layers, low cells, obvious atypia, and increased mitosis in the nucleus.

\section{Raman spectral data acquisition}

A confocal Raman micro-spectrometer (LabRAM HR Evolution, Horiba France SAS, Villeneuve d'Ascq, France) was used to record the spectrum. A 532-nm laser source was adopted, and the laser power was $25 \mathrm{~mW}$. Raman spectra in the range of 400-1800 $\mathrm{cm}^{-1}$ were collected using a 50 (NA = 0.5 ) focal length lens. The integration time was $8 \mathrm{~s}$, and the integration was performed three times.

\section{Statistical analysis}

Four to eight spectra were collected from each tissue slice. Two hundred ninety-three spectra of cervical inflammation tissue, 157 spectra of CIN I tissue, 138 spectra of CIN II tissue, 155 spectra of CIN III tissue, 166 spectra of cervical squamous cell carcinoma tissue, and 201 spectra of cervical adenocarcinoma tissue were obtained, totaling 1110 spectra. An independent sample $t$ test was used to analyze the difference of average relative intensity of Raman spectra of six types of cervical tissues. The level of significance was set at $p \leq 0.05$. 
Then, the SVM algorithm was used to build an efficient diagnosis model to classify the six tissues. All procedure was implemented with MATLAB language.

\section{Results}

\section{Raman spectroscopy}

\section{Raman spectrum analysis}

As seen from Fig. 2, the Raman peaks of the average Raman spectra of the 6 types of cervical tissues mainly appear at 548, 643, 708, 745, 817, 877, 951, 1002, 1061, 1127, 1170, 1239, 1303, 1369, 1449, 1504, 1560, 1618, and $1664 \mathrm{~cm}^{-1}$. The Raman peaks at 745, 817, 877, 1002, 1061, 1127, 1170, $1239,1369,1449$, and $1664 \mathrm{~cm}^{-1}$ are similar in appearance and in the same position in each sample. The Raman peaks in which there are differences in either shape or appearance or a combination of the two are primarily present at 548, 643, 708, $951,1303,1504,1560$, and $1618 \mathrm{~cm}^{-1}$, with obvious differences in Raman peaks at 519, 1270, and $1393 \mathrm{~cm}^{-1}$, marking clear differences in the Raman spectra of various cervical tissues. These differences are closely related to the corresponding changes in various biochemical components in cervical tissue with the development of cervical lesions.

For the convenience of viewing, the average spectral patterns of various types of cervical tissues in Fig. 2 were vertically translated. In order to directly reflect the relative intensity of different cervical tissue Raman characteristic peaks,
Fig. 3 and Fig. 4 show the average Raman spectral difference spectra of six types of cervical tissues and the 1 to 1 difference spectra between the average Raman spectrum of the six types of cervical tissues. From Fig. 3 and Fig. 4, the differences between the average Ramen peaks of each of the various tissue samples can be easily observed and contrasted.

Table 1 lists the tentative assignments for the primary spectral bands according to the previous literatures [7, 12-19]. It can be observed from Fig. 3 that the Raman peaks belonging to lipids, amino acids, collagen, and cytosine at 519, 548, 643, $754,817,1369,1506$, and $1618 \mathrm{~cm}^{-1}$ are the most intense in inflamed cervical tissue. At 1002, 1170 , and $1664 \mathrm{~cm}^{-1}$ belonging to phenylalanine, tyrosine, and amide I, the characteristic peaks of cervical inflammation tissue were the weakest. At $877 \mathrm{~cm}^{-1}$, a lipid-derived peak, the relative intensity of inflammatory tissue characteristic peaks is stronger than that of CIN I, CIN III, and cervical squamous cell carcinoma tissues, but weaker than that of CIN II and cervical adenocarcinoma tissues. At $951 \mathrm{~cm}^{-1}$, belonging to proteins ( $\alpha$-helix), the relative intensity of inflammatory tissue is stronger than that of CIN I, CIN III, cervical squamous cell carcinoma, and cervical adenocarcinoma, but weaker than that of CIN II. At $1239 \mathrm{~cm}^{-1}$, belonging to amide III, the relative intensity of the characteristic peak of inflammation tissue is stronger than that of CIN I, CIN II, and cervical adenocarcinoma, which is weaker than that of CIN III and cervical squamous cell carcinoma. At $1270 \mathrm{~cm}^{-1}$, belonging to phospholipids, the relative intensity of inflammatory tissue is stronger than that of CIN I, CIN II, and cervical adenocarcinoma and weaker than that of CIN III and cervical squamous cell carcinoma. At $1303 \mathrm{~cm}^{-1}$,
Fig. 2 Average Raman spectra of 6 types of cervical tissues

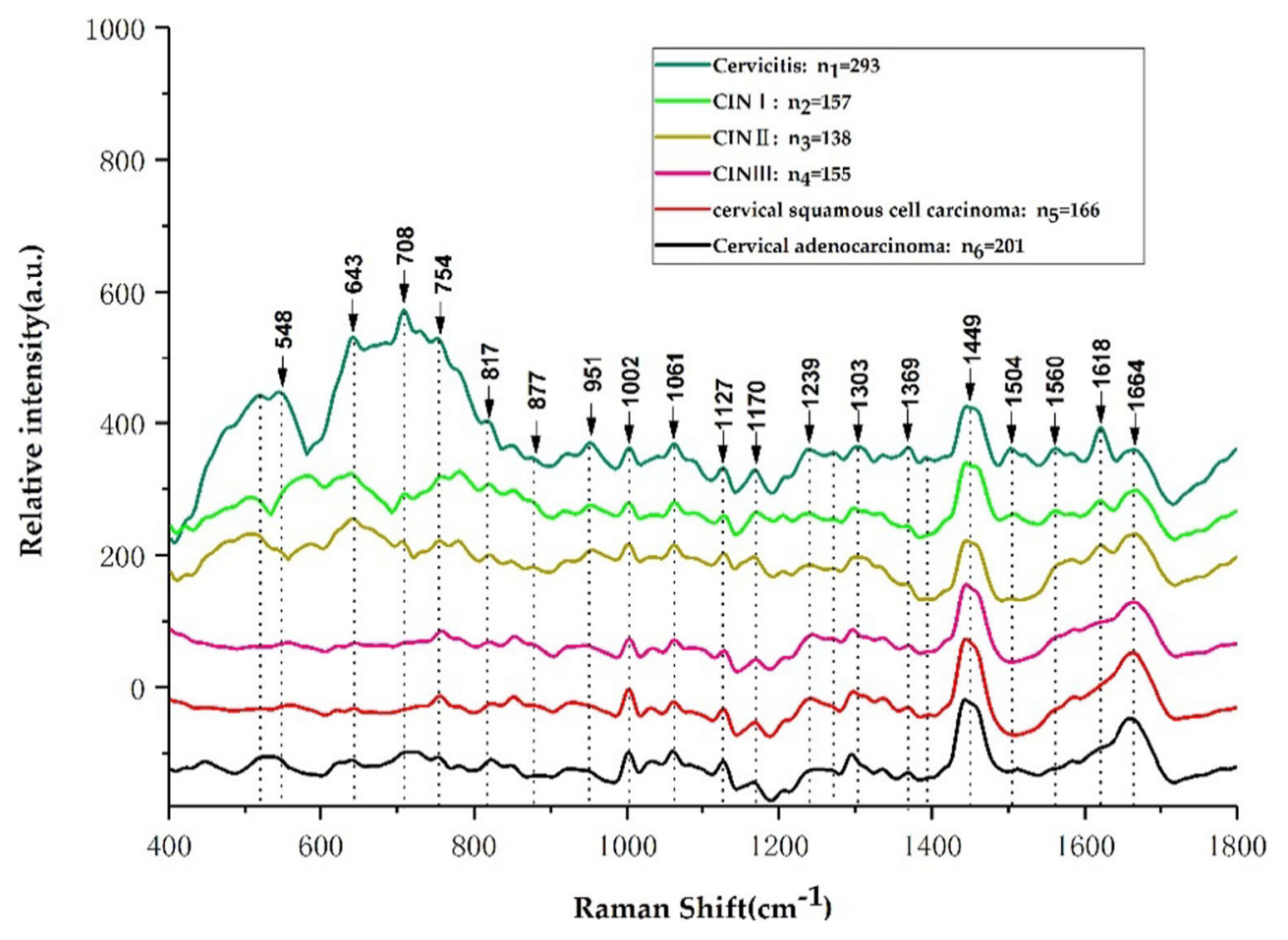




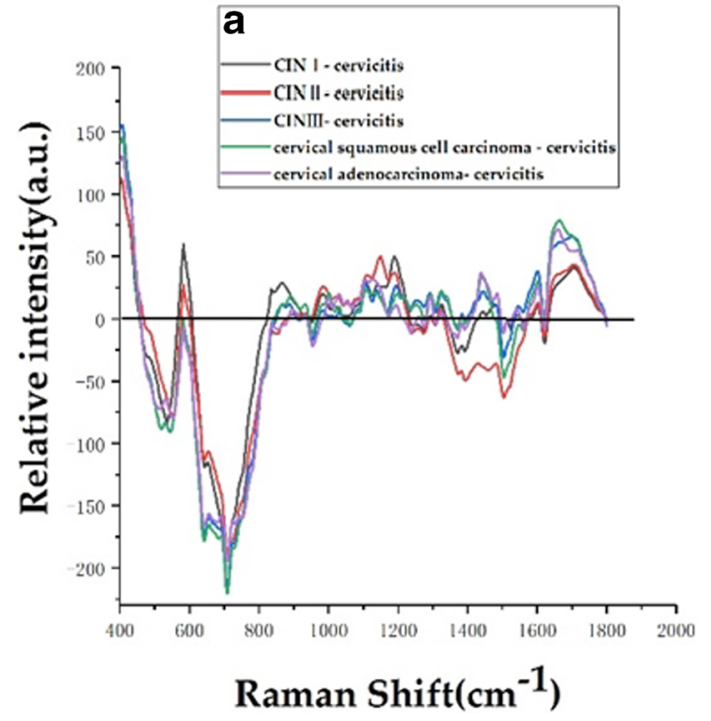

Fig. 3 Average Raman spectral difference spectra of 6 types of tissues. a The difference spectrum of the average spectrum of CIN I, CIN II, CIN III, cervical squamous cell carcinoma, and cervical adenocarcinoma minus the average spectrum of cervical inflammation. b A plot of the following: CIN I mean spectrum - average spectrum of cervical inflammation, CIN II mean spectrum - CIN I mean spectrum, CIN III mean

belonging to collagen, the relative intensity of inflammatory tissue characteristic peaks is stronger than that of CIN I and

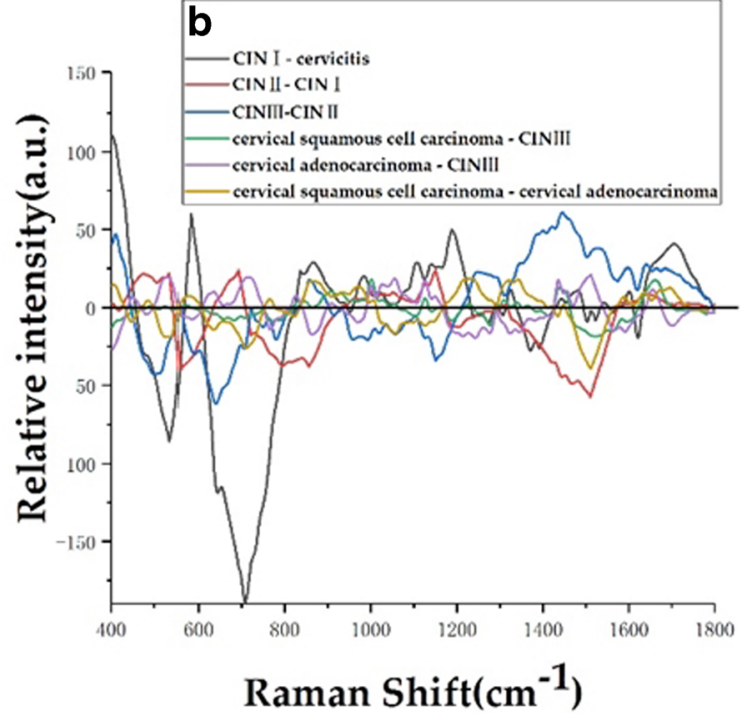

spectrum - CIN II mean spectrum, average spectrum of cervical squamous cell carcinoma - CIN III mean spectrum, average spectrum of cervical adenocarcinoma - CIN III mean spectrum, and the average spectrum of cervical squamous cell carcinoma - the difference spectrum of the average spectrum of cervical adenocarcinoma

CIN II tissue and weaker than that of CIN III, cervical squamous cell carcinoma, and cervical adenocarcinoma. At
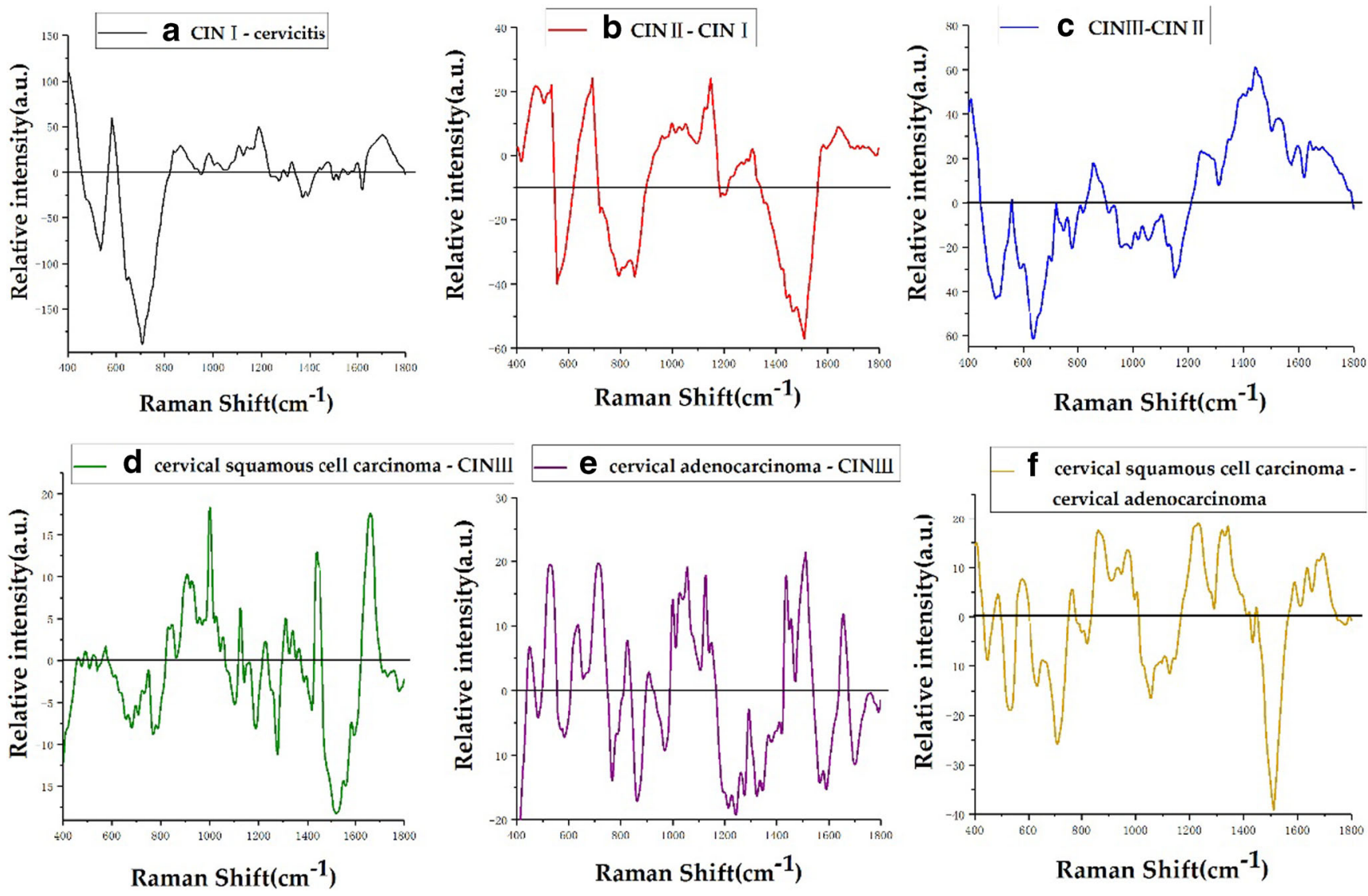

Fig. 4 a-f Average Raman spectra of 6 types of cervical tissues based on the 1 to 1 difference spectra 
Table 1 The peak positions and tentative assignments of the primary Raman bands

\begin{tabular}{|c|c|c|}
\hline Raman peak $\left(\mathrm{cm}^{-1}\right)$ & Assignment & References \\
\hline 477 & Polysaccharides, amylose & {$[13]$} \\
\hline 481 & DNA & {$[14]$} \\
\hline $495-516$ & Amino acid and cysteine & {$[13]$} \\
\hline 519 & Phosphatidylinositol & {$[14-16]$} \\
\hline 538 & Cholesterol ester & {$[14]$} \\
\hline 548 & Cholesterol & {$[14-16]$} \\
\hline 576 & Phosphatidylinositol & {$[14]$} \\
\hline 630 & Glycerol & {$[14]$} \\
\hline 643 & Tyrosine & {$[14-16]$} \\
\hline 754 & Symmetric breathing of tryptophan (protein assignment) & {$[12,17,18]$} \\
\hline 766 & Pyrimidine ring breathing mode & {$[14]$} \\
\hline 780 & Uracil-based ring breathing mode & {$[14]$} \\
\hline 788 & DNA & {$[14]$} \\
\hline 817 & $\mathrm{C}-\mathrm{C}$ stretching (collagen assignment) & {$[14-16]$} \\
\hline 826 & DNA & {$[14]$} \\
\hline 830 & Tyrosine & {$[13]$} \\
\hline 855 & Proline, tyrosine & {$[15]$} \\
\hline 859 & Tyrosine, collagen & {$[14]$} \\
\hline 867 & Ribose vibration, one of the distinct RNA modes & {$[19]$} \\
\hline 877 & Lipids & {$[14]$} \\
\hline 928 & Proline, valine (protein band) & {$[14]$} \\
\hline 951 & Proteins $(\alpha$-helix $)$ & {$[14]$} \\
\hline 968 & Lipids & {$[18]$} \\
\hline 970 & Phosphate monoester groups of phosphorylated proteins and cellular nucleic acids & {$[18]$} \\
\hline 1000 & Phenylalanine & {$[17]$} \\
\hline 1002 & Phenylalanine & {$[14]$} \\
\hline 1004 & Phenylalanine (of collagen) & {$[14]$} \\
\hline 1025 & Glycogen & {$[18]$} \\
\hline 1030 & Phenylalanine of collagen & {$[14]$} \\
\hline 1053 & $\mathrm{C}-\mathrm{O}$ stretching, $\mathrm{C}-\mathrm{N}$ stretching (protein) & {$[19]$} \\
\hline 1057 & Lipids & {$[18]$} \\
\hline 1104 & Phenylalanine (proteins) & {$[14]$} \\
\hline 1124 & Lipids & 14 \\
\hline 1128 & $\mathrm{C}-\mathrm{N}$ stretching (proteins) & {$[14]$} \\
\hline 1150 & Glycogen & {$[18]$} \\
\hline 1158 & Proteins & {$[14]$} \\
\hline 1170 & $\mathrm{C}-\mathrm{H}$ in-plane bending mode of tyrosine & {$[14]$} \\
\hline 1230 & Anti-symmetric phosphate stretching vibration & {$[18]$} \\
\hline 1243 & Amide III & {$[13]$} \\
\hline 1246 & Amide III (of collagen) & {$[14]$} \\
\hline 1275 & Amide III & {$[13]$} \\
\hline 1290 & Cytosine & {$[14]$} \\
\hline 1303 & Collagen & {$[14]$} \\
\hline 1309 & $\mathrm{CH} 3 / \mathrm{CH} 2$ twisting or bending mode of lipid/collagen & {$[14]$} \\
\hline 1320 & G (DNA/RNA) & {$[14]$} \\
\hline 1339 & $\mathrm{C}-\mathrm{C}$ stretch of phenylalanine & {$[14]$} \\
\hline 1365 & Tryptophan & {$[14]$} \\
\hline 1369 & Guanine, TRP (protein), porphyrins, lipids & {$[14-16]$} \\
\hline 1437 & $\mathrm{CH} 2$ deformation (lipid) & {$[14]$} \\
\hline
\end{tabular}


Table 1 (continued)

\begin{tabular}{|c|c|c|}
\hline Raman peak $\left(\mathrm{cm}^{-1}\right)$ & Assignment & References \\
\hline 1445 & $\mathrm{CH} 3 / \mathrm{CH} 2$ bending modes of collagen and phospholipids & {$[15]$} \\
\hline 1510 & A (ring breathing modes in the DNA bases) & [19] \\
\hline 1560 & Tryptophan & {$[14]$} \\
\hline 1583 & Phenylalanine & {$[14]$} \\
\hline 1618 & Tryptophan (protein assignment) & {$[14-16]$} \\
\hline 1637 & Amide I band & [7] \\
\hline 1645 & Amide I ( $\alpha$-helix) & {$[14]$} \\
\hline 1654 & Amide I (collagen assignment) & {$[16]$} \\
\hline 1697 & Amide I (turns and bands) & {$[14]$} \\
\hline $1185-300$ & Anti-symmetric phosphate vibrations & {$[12]$} \\
\hline $1437-53$ & $\mathrm{CH} 2$ deformation & {$[14]$} \\
\hline 1506 & Cytosine & {$[12,17,18]$} \\
\hline $1520-38$ & Carotenoid & {$[14]$} \\
\hline 1588 & Phenylalanine, hydroxyproline & {$[14]$} \\
\hline $1600-800$ & Amide I & [19] \\
\hline 1640 & Amide I band (protein band) & {$[14]$} \\
\hline $1655-80$ & Amide I (proteins) & {$[14]$} \\
\hline 1664 & Amide I & {$[14]$} \\
\hline $1700-50$ & Amino acids aspartic acid and glutamic acid & {$[13]$} \\
\hline
\end{tabular}

$1449 \mathrm{~cm}^{-1}$, belonging to $\mathrm{CH}$ vibration (proteins) and $\mathrm{CH}$ vibration (lipids), the relative intensity of inflammatory tissue characteristic peaks is weaker than that of CIN I, CIN III, cervical squamous cell carcinoma, and cervical adenocarcinoma and stronger than that of CIN II. At $1560 \mathrm{~cm}^{-1}$, belonging to tryptophan, the relative intensity of inflammatory tissue characteristic peaks was stronger than that of CIN I, CIN II, cervical squamous cell carcinoma, and cervical adenocarcinoma and weaker than that of CIN III tissue. The relative intensity of the Raman characteristic peaks can well reflect the concentration and content of the corresponding biochemical components in cervical inflammation tissue and cervical precancerous lesions (CIN I, CIN II, CIN III) and cervical squamous cell carcinoma. The difference in the relative intensity of the Raman characteristic peak between cancers reflects the obvious biochemical difference between the inflamed tissue and the other five types of cervical tissue, indicating that the biochemistry of cervical tissue changes throughout the development of cervical lesions.

Figure $4 \mathrm{~b}$ shows the difference spectra of CIN II-CIN I. The positive peaks at 477, 538, 692, and $1000 \mathrm{~cm}^{-1}$ are attributable to polysaccharides, cholesterol ester, amino acids, and methionine, respectively. Among phenylalanine peaks, $1030 \mathrm{~cm}^{-1}$ is associated with collagen, 1053 and $1128 \mathrm{~cm}^{-1}$ belong to protein, $1150 \mathrm{~cm}^{-1}$ belongs to glycogen, $1290 \mathrm{~cm}^{-1}$ belongs to cytosine, $1313 \mathrm{~cm}^{-1}$ corresponds to the twisting mode of collagen and lipids, $1583 \mathrm{~cm}^{-1}$ belongs to phenylalanine, and $1645 \mathrm{~cm}^{-1}$ belongs to amide I ( $\alpha$-helix). The negative peaks mainly appear at $788 \mathrm{~cm}^{-1}$ (DNA), $855 \mathrm{~cm}^{-1}$ (proline, tyrosine), and $1510 \mathrm{~cm}^{-1}$ (ring breathing modes in the DNA bases). Figure $4 \mathrm{c}$ shows the difference spectra of CIN III-CIN II. It can be seen that the positive peaks mainly appear at $859 \mathrm{~cm}^{-1}$, belonging to tyrosine and collagen; $1246 \mathrm{~cm}^{-1}$, attributed to amide III (of collagen); and

Table 2 Independent sample $t$ test of the average relative intensity of six kinds of cervical tissue Raman spectra

\begin{tabular}{lc}
\hline Cervical tissue type & $p$ value \\
\hline Cervicitis vs. CIN I & 0.001 \\
Cervicitis vs. CIN II & 0.000 \\
Cervicitis vs. CIN III & 0.000 \\
Cervicitis vs. cervical squamous cell carcinoma & 0.000 \\
Cervicitis vs. cervical adenocarcinoma & 0.000 \\
CIN I vs. CIN II & 0.000 \\
CIN I vs. CIN III & 0.001 \\
CIN I vs. cervical squamous cell carcinoma & 0.000 \\
CIN I vs. cervical adenocarcinoma & 0.000 \\
CIN II vs. CIN III & 0.002 \\
CIN II vs. cervical squamous cell carcinoma & 0.046 \\
CIN II vs. cervical adenocarcinoma & 0.020 \\
CIN III vs. cervical squamous cell carcinoma & 0.282 \\
CIN III vs. cervical adenocarcinoma & 0.435 \\
Cervical squamous cell carcinoma vs. cervical adenocarcinoma & 0.762 \\
\hline
\end{tabular}


Table 3 The relative intensities of representative characteristic peaks of lipids $\left(877 \mathrm{~cm}^{-1}\right)$, proteins $\left(1002 \mathrm{~cm}^{-1}\right)$, and nucleic acids $\left(1510 \mathrm{~cm}^{-1}\right)$ in six types of cervical tissues

\begin{tabular}{lccc}
\hline Cervical tissue type & Relative intensity $\left(877 \mathrm{~cm}^{-1}\right)$ & Relative intensity $\left(1002 \mathrm{~cm}^{-1}\right)$ & Relative intensity $\left(1510 \mathrm{~cm}^{-1}\right)$ \\
\hline Cervicitis & -6.82 & 8.67 & 2.62 \\
CIN I & 18.56 & 17.06 & 0.19 \\
CIN II & -7.34 & 26.97 & -22.04 \\
CIN III & 2.87 & 11.23 & -56.93 \\
Cervical squamous cell carcinoma & 5.18 & 29.22 & -39.59 \\
Cervical adenocarcinoma & -11.06 & 24.49 & -1.03 \\
\hline
\end{tabular}

$1445 \mathrm{~cm}^{-1}$, attributed to $\mathrm{CH} 3$ and $\mathrm{CH} 2$ bending modes of collagen and phospholipids. In the examination of the bending modes of collagen and phospholipids, we found that $1520-38 \mathrm{~cm}^{-1}$ belongs to carotenoid, $1600-800 \mathrm{~cm}^{-1}$ belongs to amide I, and $1640 \mathrm{~cm}^{-1}$ belongs to amide I (protein band). The negative peaks mainly appear at 495 $516 \mathrm{~cm}^{-1}$ belonging to amino acid and cysteine, $780 \mathrm{~cm}^{-1}$ is associated with uracil-based ring breathing mode, and $1158 \mathrm{~cm}^{-1}$ is associated with proteins. Figure $4 \mathrm{~d}$ shows difference spectra of cervical squamous cell carcinomaCIN III. It can be seen that the positive peaks are mainly at $830 \mathrm{~cm}^{-1}$, belonging to tyrosine; $928 \mathrm{~cm}^{-1}$, corresponding to amino acids; and $1000 \mathrm{~cm}^{-1}$, belonging to phenylalanine. Additionally, $1025 \mathrm{~cm}^{-1}$ is attributable to glycogen, $1053 \mathrm{~cm}^{-1}$ belongs to protein, $1309 \mathrm{~cm}^{-1}$ belongs to the $\mathrm{CH} 3 / \mathrm{CH} 2$ twisting or bending mode of lipid/collagen, $1339 \mathrm{~cm}^{-1}$ belongs to $\mathrm{CC}$ stretch of phenylalanine, $1365 \mathrm{~cm}^{-1}$ belongs to tryptophan, $1437-53 \mathrm{~cm}^{-1}$ belongs to $\mathrm{CH} 2$ deformation of lipid, and $1655-80 \mathrm{~cm}^{-1}$ belongs to amide I (proteins); negative peaks mainly appear at $766 \mathrm{~cm}^{-1}$ belonging to the pyrimidine ring breathing mode, $1104 \mathrm{~cm}^{-1}$ belonging to phenylalanine (proteins), 1185$300 \mathrm{~cm}^{-1}$ belonging to anti-symmetric phosphate vibrations, and $1275 \mathrm{~cm}^{-1}$ belonging to amide III. Figure 4e shows difference spectra of cervical adenocarcinoma-CIN III. It can be seen that the positive peak is mainly at $447 /$ $54 \mathrm{~cm}^{-1}$ at ring torsion of phenylalanine, $634 \mathrm{~cm}^{-1}$ attributed to amino acid and methionine, $826 \mathrm{~cm}^{-1}$ belonging to DNA, $1025 \mathrm{~cm}^{-1}$ belonging to glycogen, $1057 \mathrm{~cm}^{-1}$ belonging to lipids, $1437 \mathrm{~cm}^{-1}$ belonging to $\mathrm{CH} 2$ deformation (lipid), $1510 \mathrm{~cm}^{-1}$ belonging to ring breathing modes in the DNA bases, and $1654 \mathrm{~cm}^{-1}$ belonging to amide I (collagen assignment); the negative peak mainly appears at $481 \mathrm{~cm}^{-1}$ belonging to DNA, $766 \mathrm{~cm}^{-1}$ belonging to pyrimidine ring breathing mode, $968 \mathrm{~cm}^{-1}$ belonging to lipids, $1243 \mathrm{~cm}^{-1}$ belonging to amide III, $1560 \mathrm{~cm}^{-1}$ belonging to tryptophan, and $1700-50 \mathrm{~cm}^{-1}$ belonging to amino acids aspartic acid and glutamic acid. Figure $3 \mathrm{f}$ shows difference spectra of cervical squamous cell carcinoma-cervical adenocarcinoma. It can be seen that the positive peak mainly occurs at $576 \mathrm{~cm}^{-1}$ belonging to phosphatidylinositol, $766 \mathrm{~cm}^{-1}$ belonging to the pyrimidine ring breathing mode, and $867 \mathrm{~cm}^{-1}$ belonging to ribose vibration. Of the distinct RNA modes, $970 \mathrm{~cm}^{-1}$ belongs to phosphate monoester groups of phosphorylated proteins and cellular nucleic acids, $1004 \mathrm{~cm}^{-1}$ belongs to phenylalanine (of collagen), $1230 \mathrm{~cm}^{-1}$ belongs to antisymmetric phosphate stretching vibration, $1320 \mathrm{~cm}^{-1}$ belongs to $\mathrm{G}$ (DNA/RNA), $1588 \mathrm{~cm}^{-1}$ belongs to phenylalanine and hydroxyproline, $1637 \mathrm{~cm}^{-1}$ belongs to the amide I band, and $1697 \mathrm{~cm}^{-1}$ belongs to amide I (turns and bands). The negative peaks are mainly found in $630 \mathrm{~cm}^{-1}$, belonging to glycerol; $1057 \mathrm{~cm}^{-1}$, corresponding to lipids; $1124 \mathrm{~cm}^{-1}$, associated with lipids; and $1510 \mathrm{~cm}^{-1}$, belonging to A (ring breathing modes in the DNA bases).

There is a significant difference between the mean Raman spectra of the six types of cervical tissues, and these differences can be used to identify the six types of cervical tissues. Then, SVM was used to establish a classification model for the six types of cervical tissues.

Table 4 Classification results of SVM algorithm

\begin{tabular}{|c|c|c|c|c|c|}
\hline Style polynomial & $N($ train $) / N($ test $)$ & Correct & Fault & Total & Accuracy \\
\hline Cervicitis & $258 / 35$ & 27 & 8 & 293 & $77.14 \%$ \\
\hline CIN I & $122 / 35$ & 31 & 4 & 157 & $88.57 \%$ \\
\hline CIN II & $103 / 35$ & 28 & 7 & 138 & $80 \%$ \\
\hline CIN III & $120 / 35$ & 29 & 6 & 155 & $82.86 \%$ \\
\hline Cervical squamous cell carcinoma & $131 / 35$ & 35 & 0 & 166 & $100 \%$ \\
\hline Cervical adenocarcinoma & $166 / 35$ & 30 & 5 & 201 & $85.71 \%$ \\
\hline
\end{tabular}




\section{Statistical analysis results}

Table 2 lists the independent sample $t$ test of the average relative intensity of six kinds of cervical tissue Raman spectra. And Table 3 lists the relative intensities of representative characteristic peaks of lipids, proteins, and nucleic acids in six types of cervical tissues.

There were significant differences in the average Raman spectra of the 6 types of cervical tissues, which could be used to identify the 6 types of cervical tissues. In this study, six types of cervical tissues were classified by SVM.

In this study, the Raman spectra of six types of cervical lesions were analyzed comprehensively for the first time, and the six types of cervical lesions were classified by Raman spectroscopy combined with support vector machine. The svmtrain function is used to build the classification mod$\mathrm{el}$, and the function parameters are set to "-t 1 -c 2 -g 0.02", where $t$ represents the type of kernel function and $\mathrm{c}$ and $\mathrm{g}$ represent penalty parameter and kernel parameter, respectively. After repeated experiments, the classification effect is better.

A total of 1110 original Raman spectra of cervical tissue were used in the SVM classification model (293 spectra of cervical inflammation tissue, 157 spectra of CIN I tissue, 138 spectra of CIN II tissue, 155 spectra of CIN III tissue, 166 spectra of cervical squamous cell carcinoma, and 201 spectra of cervical adenocarcinoma). Thirty-five spectra were randomly selected from the original Raman spectra of various cervical tissues as test set data for modeling, and the remaining 900 spectra were used as training set data. The correct rate of classification is shown in Table 4, and the overall accuracy rate is $85.7 \%$, based on the established SVM classification model, which indicated that Raman spectroscopy combined with support vector machine could be used to successfully classify cervical inflammation, cervical precancerous lesions (CIN I, CIN II, CIN III), and cervical cancer (cervical squamous cell carcinoma, cervical adenocarcinoma).

\section{Discussion}

In this study, a confocal Raman micro-spectrometer was used to analyze 6 types of cervical tissues (cervical inflammation, CIN I, CIN II, CIN III, cervical squamous cell carcinoma, and cervical adenocarcinoma), and a total of 1110 Raman spectra were obtained. The average Raman spectra of six types of cervical tissues (Fig. 2), the difference spectra of average Raman spectra (Fig. 3), and the difference spectra of average Raman spectra of one to one (Fig. 4) were drawn, compared, and analyzed. The main Raman characteristic peaks of six types of cervical tissues were summarized, and the differences of biochemical components of six types of cervical tissues were analyzed. This study reveals that with the development of cervical lesions (cervical inflammation $\rightarrow$ CIN I $\rightarrow$ CIN II $\rightarrow \mathrm{CIN} \mathrm{III} \rightarrow$ cervical cancer), the biochemical components of cervical tissues are also changing. It also reveals that there are significant differences in biochemical components between cervical squamous cell carcinoma and cervical adenocarcinoma.

\section{Conclusion}

It was concluded that Raman spectroscopy combined with SVM can successfully classify cervicitis, cervical precancerous lesions (CIN I, CIN II, CIN III), cervical cancer (cervical squamous cell carcinoma, cervical adenocarcinoma), and the accuracy of six cervical tissues is $85.7 \%$. This study is expected to provide a new method for the clinical diagnosis of cervical lesions.

Funding This work was supported by the State Key Laboratory of Pathogenesis, Prevention and Treatment of High Incidence Diseases in Central Asia (PPTHIDCA) Fund (SKL-HIDCA-2018-29, SKL-HIDCA2017-7); the National Natural Science Foundation of China (NSFC) (Grant Nos. 62071059, 61765014); and the Xinjiang Uygur Autonomous Region Science and Technology Branch (2019E0282).

\section{Compliance with ethical standards}

Conflict of interest The authors declare that they have no conflict of interest.

Open Access This article is licensed under a Creative Commons Attribution 4.0 International License, which permits use, sharing, adaptation, distribution and reproduction in any medium or format, as long as you give appropriate credit to the original author(s) and the source, provide a link to the Creative Commons licence, and indicate if changes were made. The images or other third party material in this article are included in the article's Creative Commons licence, unless indicated otherwise in a credit line to the material. If material is not included in the article's Creative Commons licence and your intended use is not permitted by statutory regulation or exceeds the permitted use, you will need to obtain permission directly from the copyright holder. To view a copy of this licence, visit http://creativecommons.org/licenses/by/4.0/.

\section{References}

1. Bray F, Ferlay J, Soerjomataram I et al (2018) Global cancer statistics 2018: GLOBOCAN estimates of incidence and mortality worldwide for 36 cancers in 185 countries. CA-Cancer J Clin 68: 394-424. https://doi.org/10.3322/caac.21492

2. Chen W, Zheng R, Baade PD et al (2016) Cancer statistics in China, 2015. CA-Cancer J Clin 66:115-132. https://doi.org/10.3322/caac. 21338

3. Torre LA, Bray F, Siegel RL et al (2015) Global cancer statistics, 2012. CA-Cancer J Clin 65:87-108. https://doi.org/10.3322/caac. 21262 
4. Teng N, Abu-Rustum BNR et al (2004) Cervical cancer guidelines. Clinical practice guidelines in oncology. J Natl Compr Canc Ne 2: 612-630

5. Kallaway C, Almond LM, Barr H et al (2013) Advances in the clinical application of Raman spectroscopy for cancer diagnostics. Photodiagn Photodyn Ther 10:207-219. https://doi.org/10.1016/j. pdpdt.2013.01.008

6. Rashid N, Nawaz H, Poon KWC et al (2014) Raman microspectroscopy for the early detection of pre-malignant changes in cervical tissue. Exp Mol Pathol 97:554-564. https://doi.org/10. 1016/j.yexmp.2014.10.013

7. Faolain EO, Hunter MB, Byrne JM et al (2005) A study examining the effects of tissue processing on human tissue sections using vibrational spectroscopy. Vib Spectrosc 38:121-127. https://doi. org/10.1016/j.vibspec.2005.02.013

8. Jess PR, Smith DD, Mazilu M et al Early detection of cervical neoplasia by Raman spectroscopy. Int. J. Cancer 121:2723-2728. https://doi.org/10.1002/ijc.23046

9. Kim YH, Chang B, Choi JH et al (2016) Biochemical fingerprints of human papillomavirus infection and cervical dysplasia using cervical fluids: spectral pattern investigation. Microsc Res Techniq 79:966-972. https://doi.org/10.1002/jemt.22728

10. Duraipandian $\mathrm{S}$, Zheng $\mathrm{W}, \mathrm{Ng} \mathrm{J}$ et al (2011) In vivo diagnosis of cervical precancer using Raman spectroscopy and genetic algorithm techniques. Analyst 136:4328-4336. https://doi.org/10. 1039/C1AN15296C

11. Lin D, Qiu S, Huang W et al (2018) Autofluorescence and white light imaging-guided endoscopic Raman and diffuse reflectance spectroscopy for in vivo nasopharyngeal cancer detection. J Biophotonics 11:e201700251. https://doi.org/10.1002/jbio. 201700251
12. Cordero E, Latka I, Matthäus C et al (2018) In-vivo Raman spectroscopy: from basics to applications. J Biomed Opt 23:071210. https://doi.org/10.1117/1.JBO.23.7.071210

13. Shetty G, Kedall C, Shepherd N et al (2006) Raman spectroscopy: elucidation of biochemical changes in carcinogenesis of oesophagus. Brit J Cancer 94:1460-1464. https://doi.org/10.1038/sj.bjc. 6603102

14. Movasaghi Z, Rehman S, Rehman IU (2007) Raman spectroscopy of biological tissues. Appl Spectrosc Rev 42(5):493-541. https:// doi.org/10.1080/05704920701551530

15. Huang Z, McWilliams A, Lui H et al (2003) Near-infrared Raman spectroscopy for optical diagnosis of lung cancer. Int J Cancer 107: 1047-1052. https://doi.org/10.1002/ijc. 11500

16. Frank CJ, McCreecy RL, Redd DCB (1995) Raman spectroscopy of normal and diseased human breast tissues. Anal Chem 67:777783. https://doi.org/10.1021/ac00101a001

17. Malini R, Venkatakrishma K, Kurien J (2006) Discrimination of normal, inflammatory, premalignant, and malignant oral tissue: a Raman spectroscopy study. Biopolymers 81:179-193. https://doi. org/10.1002/bip.20398

18. Dukor RK (2006) Vibrational spectroscopy in the detection of cancer. Handbook of vibrational spectroscopy. https://doi.org/10.1002/ 0470027320.s8107

19. Chan JW, Taylor DS, Zwerdling T et al (2006) Micro-Raman spectroscopy detects individual neoplastic and normal hematopoietic cells. Biophys J 90:648-656. https://doi.org/10.1529/biophysj. 105.066761

Publisher's note Springer Nature remains neutral with regard to jurisdictional claims in published maps and institutional affiliations. 